
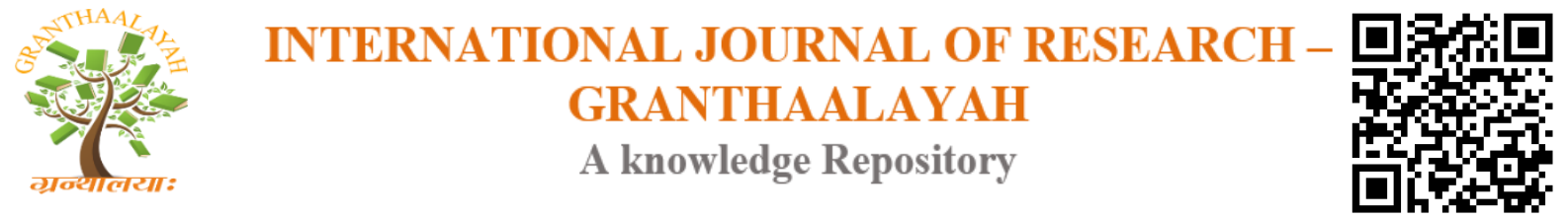

Science

\title{
PROCESSING TECHNOLOGY AND PACKAGING MATERIALS EFFECTS ON ACCEPTABILITY, STORAGE STABILITY AND SHELF LIFE OF “AADUN" (NIGERIAN MAIZE BASED SNACKS)
}

\author{
Adedokun S.O. ${ }^{1}$, Idowu M.A. ${ }^{* 2}$, Henshaw F.O. ${ }^{* 2}$ \\ ${ }^{1}$ Department of Food Science and Technology, The Oke -Ogun Polytechnic, Saki Oyo state \\ Nigeria \\ ${ }^{2}$ Department of Food Science and Technology, Federal University of Agriculture Abeokuta, \\ Ogun State, Nigeria
}

\begin{abstract}
"Aadun" is a Nigerian traditional maize based snack, but now poorly accepted by todays snack consumers despites its quality. To increase acceptability sensory panelist using 5 points ranking scores were asked to rank "Aadun" processed using laboratory equipment and traditional processed commercial samples purchased from Ibadan and Abeokuta with packaging materials of Leaf (Taumatoccous Danielle), Low Density Polyethylene (LDPE), High Density Polyethylene (HDPE), Aluminum foil (ALF) and Polystyrene plastic cup (PSC). Laboratory "aadun" packaged in different materials and the commercial samples packaged in LDPE were stored under refrigeration (4-5 0C; RH 74.85\%), ambient (25-30 0C; RH 66.7\%) and sunlight (30-44 0C; RH $65.81 \%$ ) conditions for 6 months and at 2 weeks intervals off flavor (OF) was determined by 10 trained sensory panelists and growth of microorganism by total plate count (TPC) method. Shelf life was estimated by plotting hazard (TPC) against time on linear and quadratic regression curve and safety cut off value of $105 \mathrm{cfu} / \mathrm{g}$ as limit. Results showed the highly ranked "Aadun" was Laboratory sample followed by Ibadan and Abeokuta samples and PSC ranked highest followed by ALF, HDPE, LDPE and Leaf. A longer lag period before OF and TPC increased was under Refrigeration, PSC, LDPE Laboratory and Abeokuta samples but, shorter under ambient, sunlight, leaf and LDPE Ibadan sample. Longer shelf life period was under refrigeration, PSC (42.4 weeks), LDPE laboratory (40.1 weeks), LDPE Abeokuta (33.2 weeks but shorter under ambient, sunlight, leaf (19 weeks) and LDPE Ibadan (30.5 weeks). This study shows that if modern technology and PSC packing plastic materials and storing under refrigeration conditions will improve acceptability, long storage stability and shelf life thereby, increasing production and the economy of the local women processor in Nigeria.
\end{abstract}

Keywords: "Aadun” Technology; Packaging; Acceptability; Storage Stability \& Shelf Life.

Cite This Article: Adedokun S.O., Idowu M.A., and Henshaw F.O.. (2020). "PROCESSING TECHNOLOGY AND PACKAGING MATERIALS EFFECTS ON ACCEPTABILITY, STORAGE STABILITY AND SHELF LIFE OF “AADUN" (NIGERIAN MAIZE BASED 
SNACKS)." International Journal of Research - Granthaalayah, 8(4), 243-255. https://doi.org/10.29121/granthaalayah.v8.i4.2020.30.

\section{Introduction}

"Aadun" is one of the snack foods from maize (Zya Mays) which is processed by traditional technology and is predominantly processed and consumed in Yoruba speaking areas of Nigeria [1]. It is known for its appealing reddish color (due to the addition of red palm oil), ease of disintegration in the mouth, fine texture and sweetness. It has its traditional usages in marriages, naming ceremony, and had been a snack meal for warriors, pregnant woman, young and old, rich and poor alike [1]. However, snacks made from wheat, like biscuits, cakes, etc has been highly elevated despites their health implication [11] thus making todays snacks consumers to neglect traditional snacks like "aadun" despite its high energy, fibre and minerals contents[12] remains at lower ebbs and has been confined as low income earners (poor people) snacks.

Traditional Processing methods varies within the consuming areas of Western Nigeria and processors sometimes in an attempt to increase varieties or probably to improve nutritional status add vegetative materials like beans, groundnut, tomatoes, etc. [10]. Meanwhile, traditional processing method for plain "aadun" is by manual sorting maize (Zea maize) white variety to remove impurities, roasting under atmospheric condition in an earthen pots placed on a wooden fire with continuous stirring until a golden brown colour is achieved, and then milling to flour grits by using stone or pestles and mortal $[1,12]$, but nowadays grinding with a torso disc grinding mill is common. Within the region also, mixing of the roasted flour with other ingredients such as palm oil, pepper, and common salt varied and is either by using cold or hot methods. The cold mixing method is commonly practice in states like Oyo, Osun, Ondo and Part of Ijebu division of Ogun state to gives a characteristic yellow colouration. While, hot mixing method involved the use of heating in an earth pot placed on firewood fire with continuous stirring which is commonly practice in states like Ekiti, Kwara, Kogi and Abeokuta division of Ogun state to gives a characteristics brown colouration [12].

Also, "Aadun" is usually presented to the consumers either by packaging in leafs (Taumatoccous Danielle), or left exposed in the opened uncovered as shown in (Plate 1) or bulk packaged (exposure to the atmosphere) in a transparent glass box (Plate 2). However, research report has shown effects on chemical composition of "Aadun" but scanty information exist on what effects it has on consumer attitude towards its acceptability. It could have been one of the major facts consumer are showing apathy towards patronage of "Aadun". However, it has been observed from initial investigation with processors (un-published) that in an attempt to use modern packaging materials the use of Nylon (LDPE) is been used without understanding the effects it will have on acceptability of "Aadun". Meanwhile, it has been suggested than an appropriate modern processing technology and packaging materials should be provided if traditional snacks/food has to be improve to assist local food vendors to gain more access to market, increase acceptability of their product and increase shelf life $[6,14]$. Therefore, this study evaluated the effects of using modern processing technology, packaging in different packaging materials and storage conditions on "Aadun" This is aimed to improve "Aadun" acceptability and extend it shelf life, to assist the poor local women to meet the sustainable goal. 


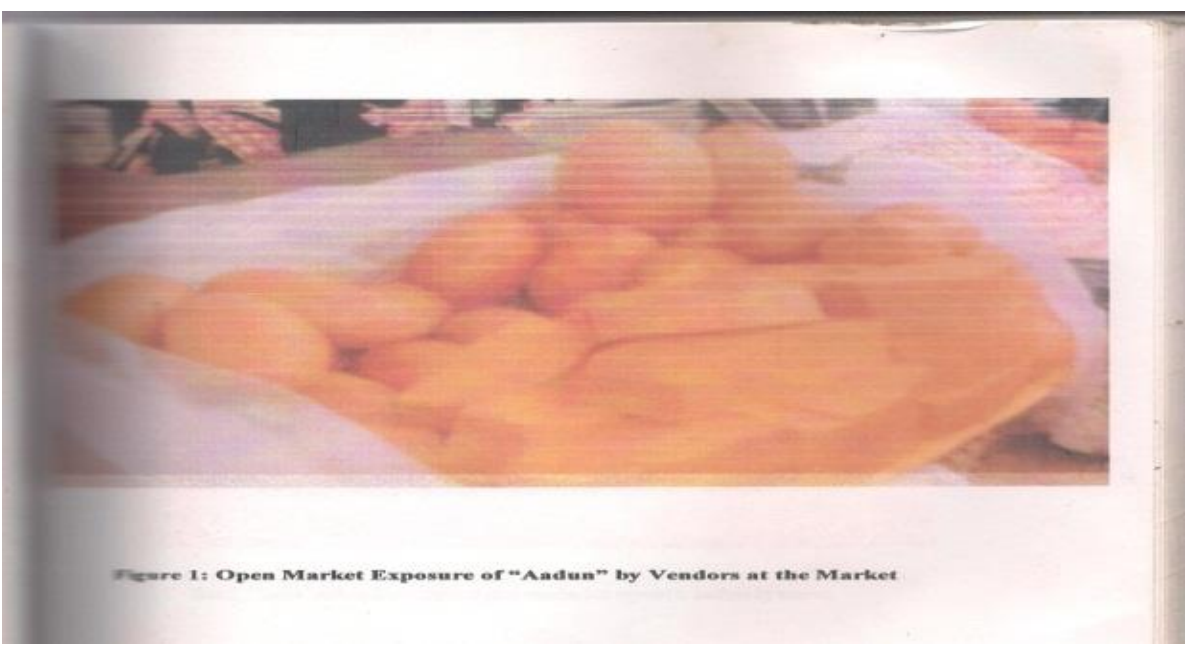

Plate 1: Exposed "Aadun" at the Market

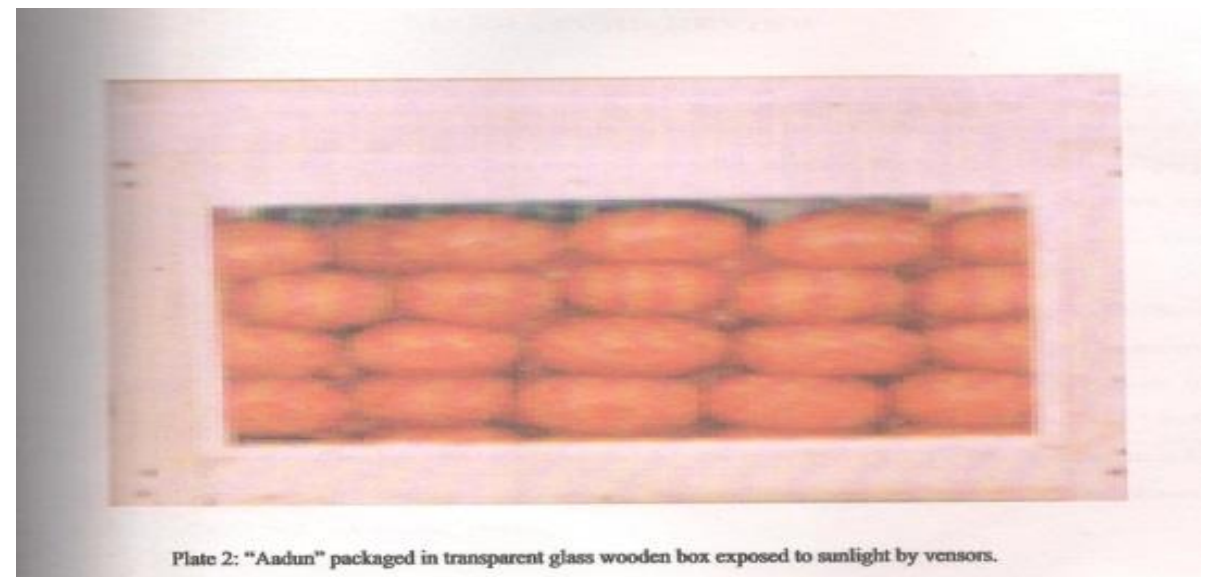

Plate 2: "Aadun" Packaged in Wooden glass

\section{Materials and Methods}

\subsection{Samples Collection and Pre-Treatment}

Maize (Zea maize) white variety, palm oil, pepper, Leaf (Taumatoccous Danielle), Low Density Polyethylene (LDPE), High Density Polyethylene (HDPE), Aluminum Foil (ALF) and Polystyrene cup (PSC) and salt were obtained from Kuto market, Abeokuta Ogun State. While commercial" aadun" sample was purchased from Ibadan and Abeokuta already exposed to the market environment and was then wrapped in Nylon (LDPE), kept in a cooler, then stored under freezing condition before usage.

\subsection{Preparation of Laboratory Sample}

To introduce modern technology, laboratory “Aadun" sample was prepared using figure 1 adapted from traditional Ibadan processing technology steps and using table 1 for the formulation. White 
maize variety of about $80 \mathrm{~kg}$ was weighed using melter PM 400 load balance. The grain was roaster in a frying pan (Aluminum) placed on a hot plate (electric Gallenkam) at a temperature of $250^{\circ} \mathrm{C}$ for 10-15 minutes with continuous starring with aluminum desert spoon to a golden brown colour. About $78 \mathrm{~kg}$ of roasted maize was obtained and was then milled together with $38 \mathrm{~kg}$ dried pepper (capsicum cayenne) into flour grits by using disk mill (Burher mill earlier washed with hot water and sanitized with chlorine). Sieving was done using EFL/MK3 test shaker sieve to obtain flour of particle size $(<0.4 \mathrm{~mm})$.

Cold mixing method of Ibadan was used to mix other ingredients like palm oil and salts with a laboratory Kenwood mixer (table1). This sample was then divided into two parts with one part used for acceptability test compared with commercial samples. While for storage stability test, the second part was portioned (25gm) into Leaf (Taumatoccous Danielle), Low Density Polyethylene (LDPE), High Density Polyethylene (HDPE), Aluminum foil (ALF) and Polystyrene plastic cup (PSC) as indicated in Plate 3 and with Ibadan and Abeokuta commercial samples packaged in LDPE (with enough samples) were packed into large plastics (3) and each were stored for 6 month under refrigeration $\left(4-5{ }^{\circ} \mathrm{C}\right.$; RH $\left.74-85 \%\right)$, ambient $\left(25-30{ }^{\circ} \mathrm{C}\right.$; RH $\left.66.7-81 \%\right)$, and sunlight condition $\left(30-44{ }^{\circ} \mathrm{C}\right.$; RH $65-75 \%$ ) condition respectively. At 2 weeks intervals, stability test of rate of off flavor and microbial growth was evaluated.

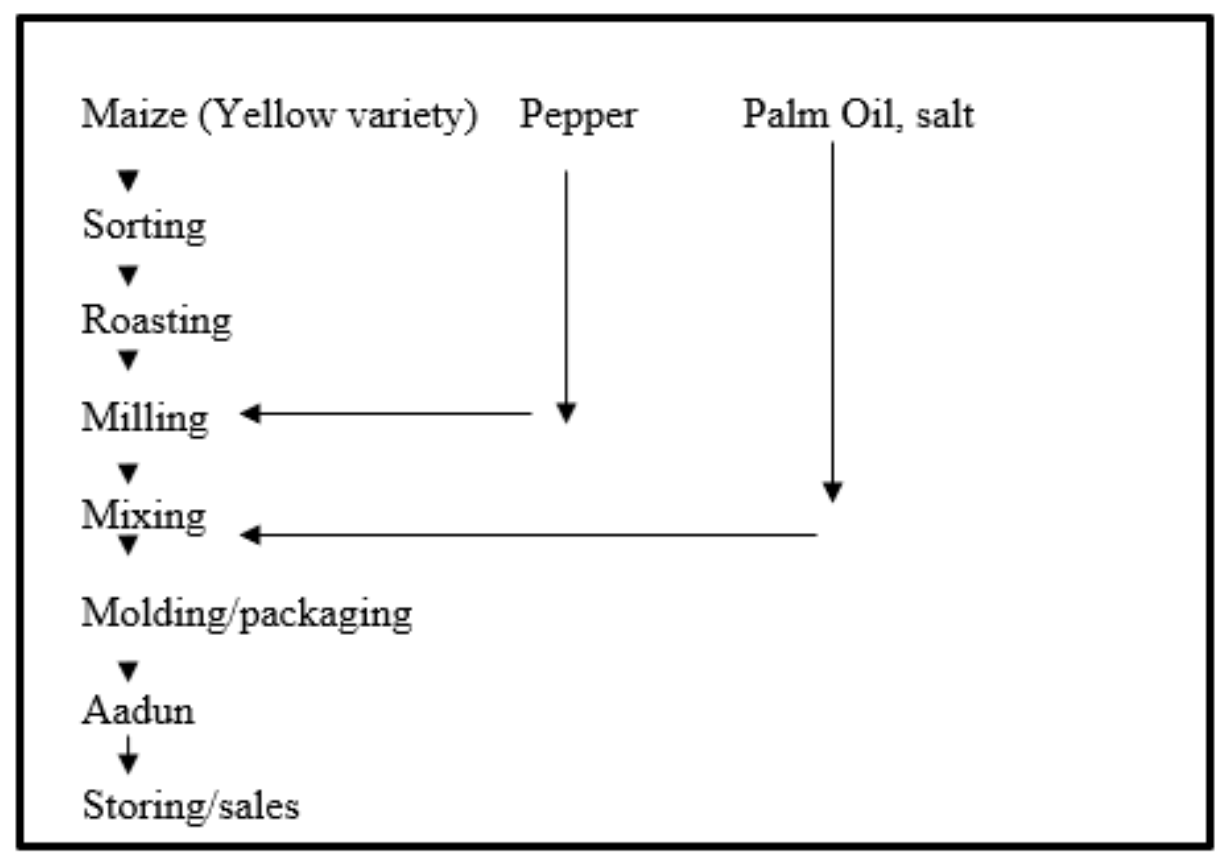

Figure 1: Processing of "Aadun" using Ibadan Traditional Production Process

Table 1: Product Formulation

\begin{tabular}{|l|l|l|}
\hline SN & Ingredients & Quantity (w/w) \\
\hline 1 & Maize (Roasted) & $78 \mathrm{~kg}$ \\
\hline 2 & Pepper & $38 \mathrm{~kg}$ \\
\hline 3 & Palm oil & $100 \mathrm{cl}$ \\
\hline 4 & Salt & $43 \mathrm{gm}$ \\
\hline
\end{tabular}




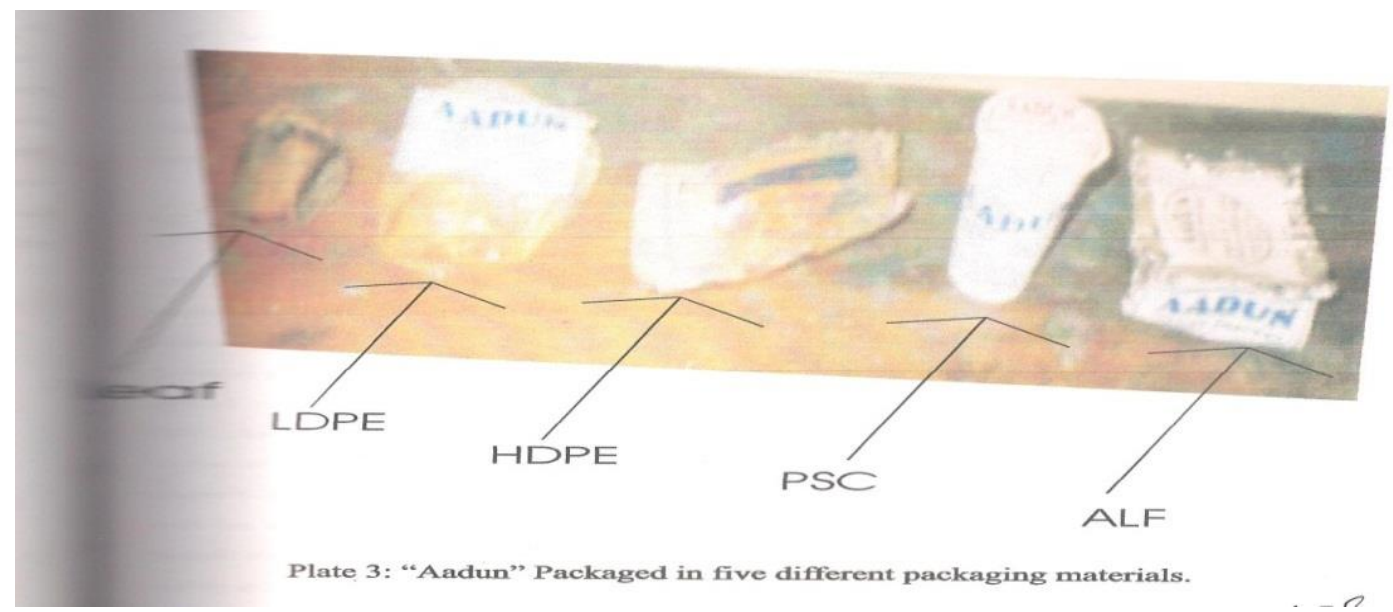

Plate 3: "Aadun" Packaged in different packaging materials

\subsection{Sensory Evaluation of "Aadun" Samples and Packaging Materials}

Laboratory and traditional processed commercial "Aadun" and different packaging materials of Leaf (Taumatoccous Danielle), Low Density Polyethylene (LDPE), High Density Polyethylene (HDPE), Aluminum foil (ALF) and Polystyrene plastic cup (PSC) indicated in appendix ii plate 3 were evaluated for sensory acceptability before portioning "aadun" into packaging materials by using a modified sensory method $[10,20]$ by using 50 members panel of judges who were familiar with the consumption of "Aadun" (mostly students). The panel was asked to rank the "aadun" samples in terms of taste, flavor, texture, appearance and general acceptability and the packaging materials in terms of appearance, convenience in handling and overall acceptability. All sensory scores were based on a 5 point ranking scale where $1=$ highly preferred; $2=$ preferred; $3=$ neither preferred nor rejected; $4=$ rejected; $5=$ highly rejected. Each panelist was provided with enough privacy to avoid biased assessment.

\subsection{Storage Stability Test}

\subsubsection{Off Flavour (Of) Changes During Storage}

During storage for six months, at 2 weeks intervals, 10 trained panelists were asked to compare freshly prepared "aadun" as Reference (R) with stored packaged "aadun" using sensory method described by $[10,11]$ to detect changes in flavor $(\mathrm{OF})$. The scoring was based on 3 point ranking scale where 1 = same as R, 2 (moderately off flavor); 3 = extremely off flavor. The result was presented graphically by plotting the hazard (off flavor scores) against time on a linear and quadratic regression curve to show rate of off flavour

\subsubsection{Microorganism Growth During Storage}

During storage for 6 months and at 2 weeks intervals, microbial growth rate was determined by using total plate count method as described by [10] modified by $[13,16]$. The stored sample was placed into laboratory plate counter and the surface total microbial growth was counted using standard counting procedure as Total plate count (TPC). The hazard (TPC) was plotted against time on a linear and quadratic regression curve to show rate of growth of microorganism. 


\subsection{Shelf Life Estimation}

The shelf life was estimated using method adapted by [8] with an equation $Y=a+b(x)$, where $Y=$ assumed cut off mean for deterioration to occur and either sensory off flavor value 3.0 as suggested by $[11,21]$ or microbial Total plate counts $10^{5} \mathrm{fu} / \mathrm{g}$ as suggested by CODEX [5] and [18]. However, for safety purpose of the consumers' microbial growth rate was used as the cut off limit for the estimation. While (a) is the intercept and (b) the gradients (rate), and (x) is the estimated period. The hazard (TPC) was plotted against time on a linear and quadratic regression curve to solve for period $(\mathrm{x})$ value [7].

\subsection{Statistical Analysis}

All sensorial data were subjected to analysis of variant (ANOVA) using SPSS (version 15.0, 2011) statistical package. The mean was separated with Duncan multiple range test (DMRT), using Microsoft Excel statistical package [17-18].

\section{Results and Discussion}

\subsection{Sensory Acceptability of "Aadun" Samples}

The mean sensory scores for laboratory and commercial "aadun" samples is shown in table 2 . The laboratory prepared "aadun" sample had the highest ranking in terms of red color which is the natural known color for "aadun" $[1,12]$ as a result of addition of red palm oil to mix the maize grits by cold mixing method which does not introduce change in color like Abeokuta sample that have brown coloration due to heating process which might have contributed to its low ranking.

Table 2: Mean Scores for "Aadun" Acceptability

\begin{tabular}{|l|c|c|c|}
\hline Parameters & \multicolumn{3}{|c|}{ "Aadun" Samples } \\
\hline $\mathbf{n = 5 0}$ & Ibadan & Abeokuta & Laboratory \\
\hline Colour & $1.68 \pm 0.65$ & $2.74 \pm 0.60$ & $1.43 \pm 0.50$ \\
\hline Flavour & $2.16 \pm 0.68$ & $1.58 \pm 0.73$ & $2.07 \pm 0.87$ \\
\hline Texture & $1.70 \pm 0.71$ & $2.50 \pm 0.72$ & $1.63 \pm 0.70$ \\
\hline Taste & $1.80 \pm 0.67$ & $1.63 \pm 0.68$ & $1.36 \pm 0.56$ \\
\hline Overall Acceptability & $1.85 \pm 0.54$ & $2.25 \pm 0.57$ & $1.51 \pm 0.46$ \\
\hline
\end{tabular}

In terms of flavor, Abeokuta sample was highly ranked followed by Laboratory and Ibadan sample ranked lowest. The high flavor noticed in Abeokuta sample must have been contributed by the heating process which often enhance flavor in foods [4]. While in terms of taste and texture, the laboratory sample was highly ranked which might have been contributed by the sieving process that gives fine texture as an improvement above the traditional processing method. This also reflects in the overall acceptability scores where the laboratory sample was highly ranked followed by Ibadan and Abeokuta sample was least in rank. 


\subsection{Sensory Acceptability of Packaging Materials}

The sensory acceptability mean ranking scores of the packaging materials is shown in table 3 . The result showed that in terms of appearance consumers preferred PSC followed by ALF, HDPE, leaf and LDPE. While in terms of convenience in handling, PSC was also highly ranked which is followed by ALF, HDPE, LDPE and leaf the least in rank. In the overall acceptability rating, PSC was generally preferred above ALF, HDPE, LDPE and Leaf was the least in rank.

Table 3: Mean Scores for Packaging Materials Acceptability

\begin{tabular}{|l|c|c|c|}
\hline Packing Material & \multicolumn{3}{|c|}{ Parameters } \\
\hline $\mathbf{n = 5 0}$ & Appearance & Handling convenience & Overall Acceptability \\
\hline LEAF & $3.09 \pm 1.32$ & $4.70 \pm 0.94$ & $3.90 \pm 1.13$ \\
\hline LDPE & $3.60 \pm 1.18$ & $3.50 \pm 1.34$ & $3.54 \pm 1.26$ \\
\hline HDPE & $2.66 \pm 0.94$ & $2.50 \pm 0.70$ & $2.60 \pm 0.82$ \\
\hline PSC & $2.00 \pm 1.18$ & $1.26 \pm 0.43$ & $1.65 \pm 0.61$ \\
\hline ALF & $2.08 \pm 1.04$ & $1.35 \pm 0.68$ & $1.72 \pm 0.86$ \\
\hline
\end{tabular}

LDPE = Low density polyethylene; $\mathrm{HDPE}=$ high density polyethylene; $\mathrm{PSC}=$ polystyrene cup; $\mathrm{ALF}=$ Aluminum foil

This result showed that modern consumers will prefer a packaging materials like PSC that have appealing appearance, ease of handling (open and closed), easily labeled and allow use of scoop spoon with ease in contrast to leave and ordinary nylon that is presently been used which has reduced wider acceptability of "aadun" among snack consumers in West Africa and in the diaspora. An innovative packaging will increase production and thus assisting the local women vendors sustainable goal as earlier suggested $[6,13]$.

\subsection{Storage Stability of "Aadun"}

\subsubsection{Off Flavour (OF) Changes During Storage}

The off flavor (OF) changes during storage in different conditions is shown in Figure 2, 3 and 4 graphically. The result shows that onset of off flavor was dictated by temperature gradient as lower temperature under the refrigeration conditions gave longer lag period of about 14 weeks before onset of OF was noticed which is shorter under ambient and sunlight condition (6weeks) which supported earlier suggestion of [3] on factors affecting microbial growth . During storage leaf showed the highest rate of OF compared to LDPE, ALF, HDPE and PSC lowest which showed that leaf have poor barrier properties to hazards like air and water that aid enzymes and microbial activities which cause food spoilage $[6,14]$. While the LDPE packaged "aadun (Laboratory and commercial) showed that Ibadan sample had the highest OF rate compared to Laboratory and Abeokuta sample the least. 


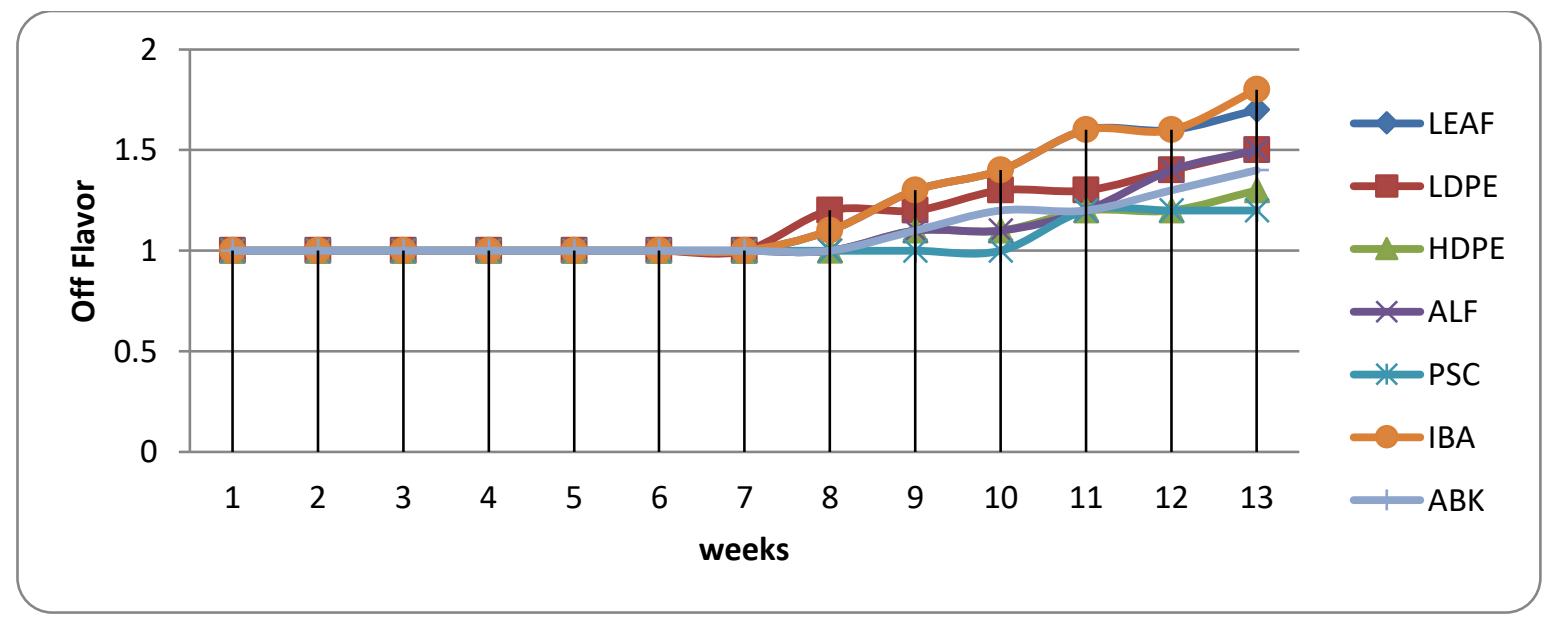

Figure 2: Off Flavor (OF) changes under Refrigeration $\left(4-5^{\circ} \mathrm{C}\right.$; $\left.\mathrm{RH} 74-85 \%\right)$ graph Packaged Samples: 1. Laboratory (LEAF, LDPE, HDPE, ALF, PSC); 2.IBA = Ibadan (LDPE) 3. $\mathrm{ABK}=$ Abeokuta $(\mathrm{LDPE})$.

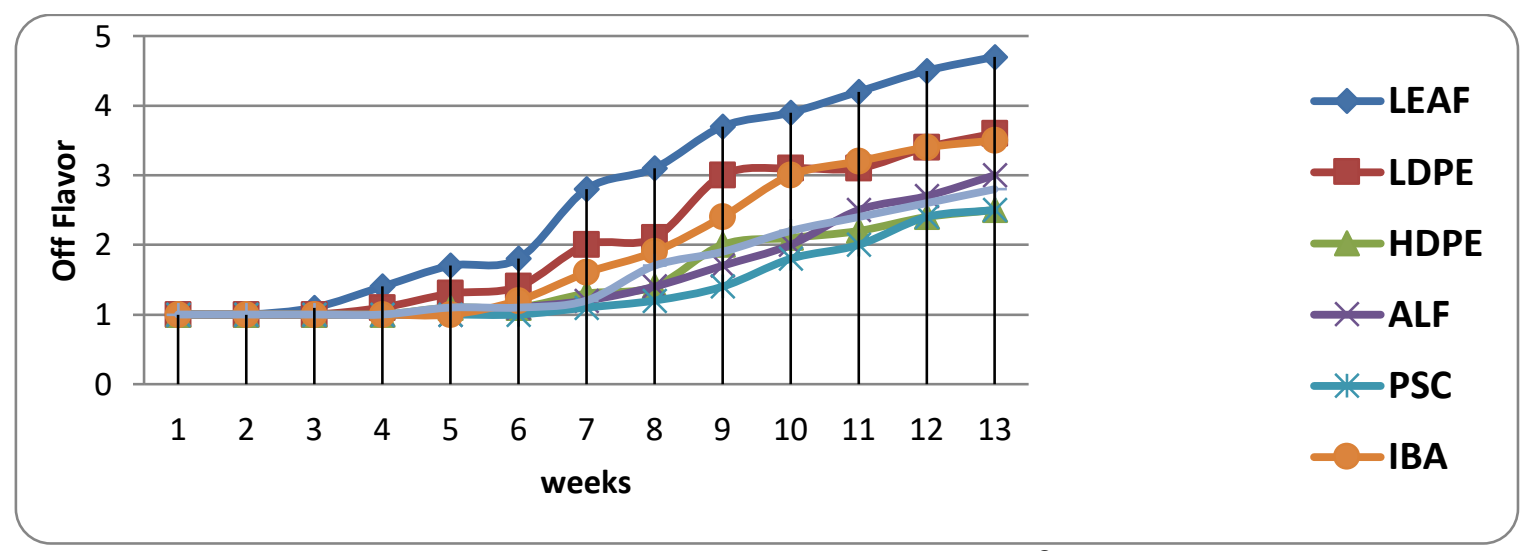

Figure 3: Off Flavour (OF) changes under Ambient $\left(25-30{ }^{\circ} \mathrm{C}\right.$; RH $\left.66.5-81 \%\right)$ graph. Packaged Samples: 1. Laboratory (LEAF, LDPE, HDPE, ALF, PSC); 2.IBA = Ibadan (LDPE) 3. $\mathrm{ABK}=$ Abeokuta (LDPE).

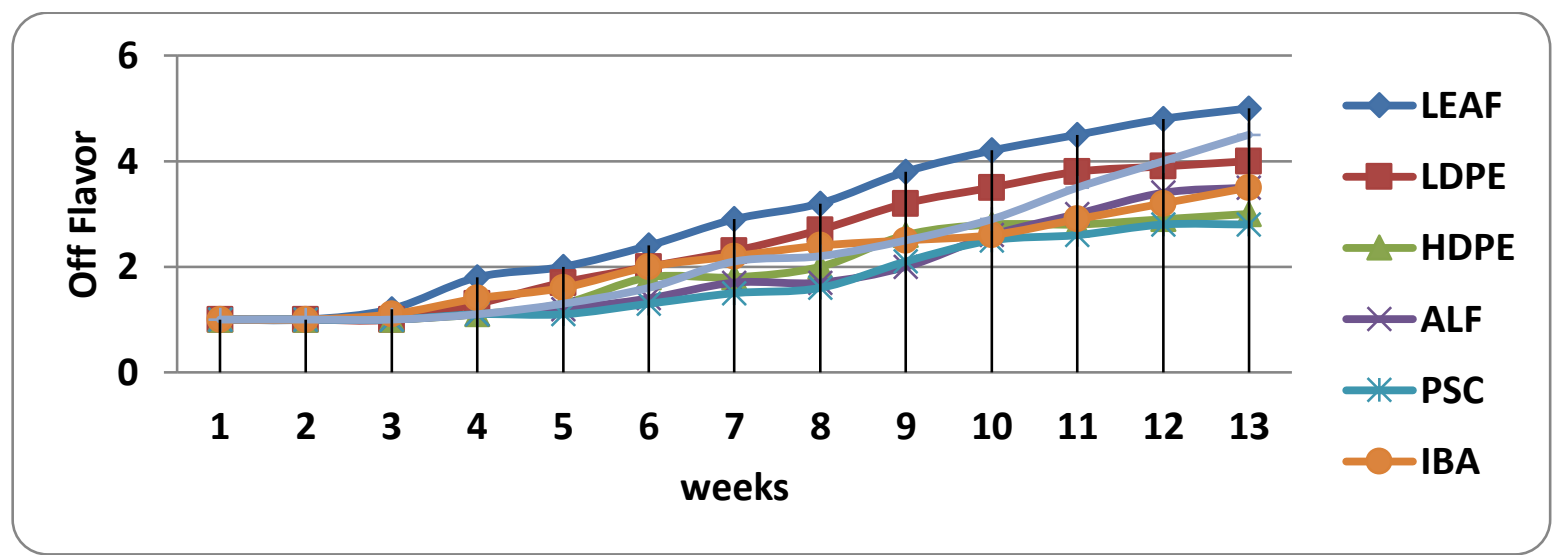

Figure 4: Off Flavour (OF) changes under sunlight $\left(30-44^{\circ} \mathrm{C}\right.$; RH 65-85\%) graph. Packaged Samples: 1. Laboratory (LEAF, LDPE, HDPE, ALF, PSC); 2.IBA = Ibadan (LDPE) 3. $\mathrm{ABK}=$ Abeokuta (LDPE). 
Food spoilage is often as a result of actions of intrinsic or extrinsic factor like enzymes, microorganism, oxygen and water under favorable high temperature to breaks down food to its smaller molecules to release off flavor (OF). In high fat foods, rancidity which is an oxidative process releases free fatty acids and others smaller molecules to gives off flavor (rancid) and it depends on the degree of saturation of its fatty acid, temperature gradient and packaging materials used [9]. Hence, the observed longer lag period before onset of OF could be noticed under refrigeration was as a result of low temperature that hinder enzymes and microbial growth and high saturation of the palm oil used, but shorter period was noticed under ambient and sunlight as a result of high temperature which encourage enzymes and microbes breakdown of food to it smaller molecules [19] in his publication of food product shelf life, how long before its gone? Also, the present high quantity of saturated fatty acids (palmitic and stearic) in palm oil has been suggested could hinder oxidation process (rancidity) in high fat foods [3].

However, behavior of the packaging must have been contributed by individual packaging materials barrier properties (porosity/ permeability rate) against hazards such as air $\left(\mathrm{O}_{2}\right.$ and $\left.\mathrm{CO}_{2}\right)$ and water under different storage condition which have effects on breaking down of food to its components [6-7, 9, 14, 22]. PSC had lower off flavor value compared to leaf, LDPE and HDPE could be as a result of its high barrier properties to these hazards hence assisted in controlling spoilage of "aadun" for a longer period. Meanwhile, the high OF shown in LDPE packaged Ibadan sample must have been as a result of poor preparation method in the used of traditional technology in terms of crude processing equipment, exposure to un-hygienic environment and packaging in LDPE which has low barrier properties [9] in contrast to the Laboratory sample which has lower values due to it preparation mode in using modern technology and under hygienic condition which has initial lower microorganism that can trigger off flavour. While the lowest OF was in Abeokuta samples which must have been as a result of hot mixing method that could have eliminated majority of the spoilage microorganism as suggested by $[3,16]$ that heat treatment reduces microbial content in food products.

\subsubsection{Microorganism Growth (TPC)}

The graph in figure 5, 6 and 7 represent the rate of growth of microorganism of different packaged "Aadun" stored under different condition. This result showed that the microbial growth rate was affected by differential temperature gradient where a longer lag period was noticed under refrigeration condition before high microbial growth was noticed in contrast to shorter lag period of increase growth under ambient which is more shorter under sunlight conditions $(14,10$ and 8 weeks) respectively. High temperature gradient such as under ambient and sunlight temperatures encourages microbial activities [3], hence increased growth was noticed. Also, high saturated fatty acid content must also have discourage microbial growth which has been shown could hinder microbial growth in food [3]. 


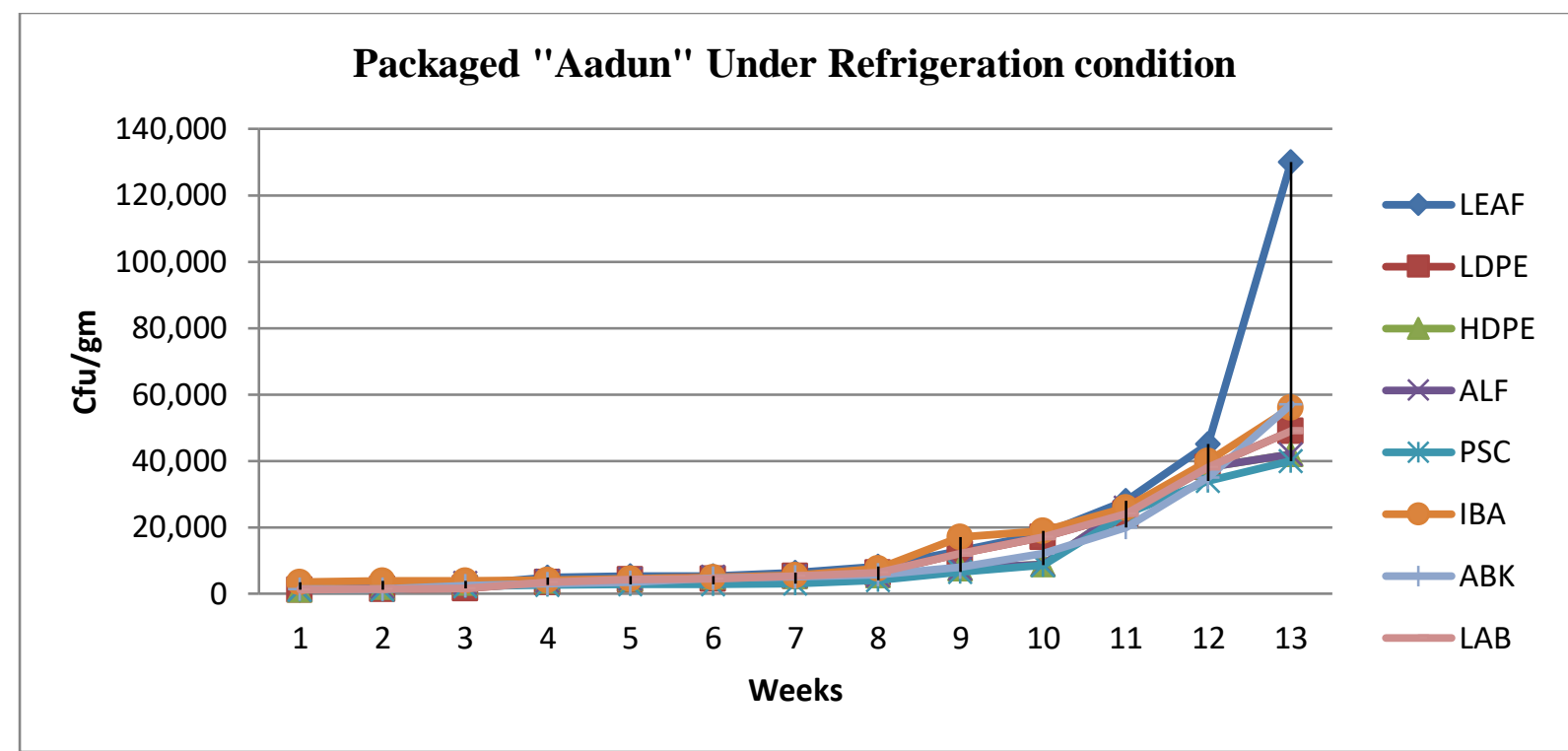

Figure 5: Microbial growth (TPC) under refrigeration condition graph;

Packaged Samples: 1. Laboratory (LEAF, LDPE, HDPE, ALF, PSC); 2.IBA = Ibadan (LDPE) 3. $\mathrm{ABK}=$ Abeokuta (LDPE).

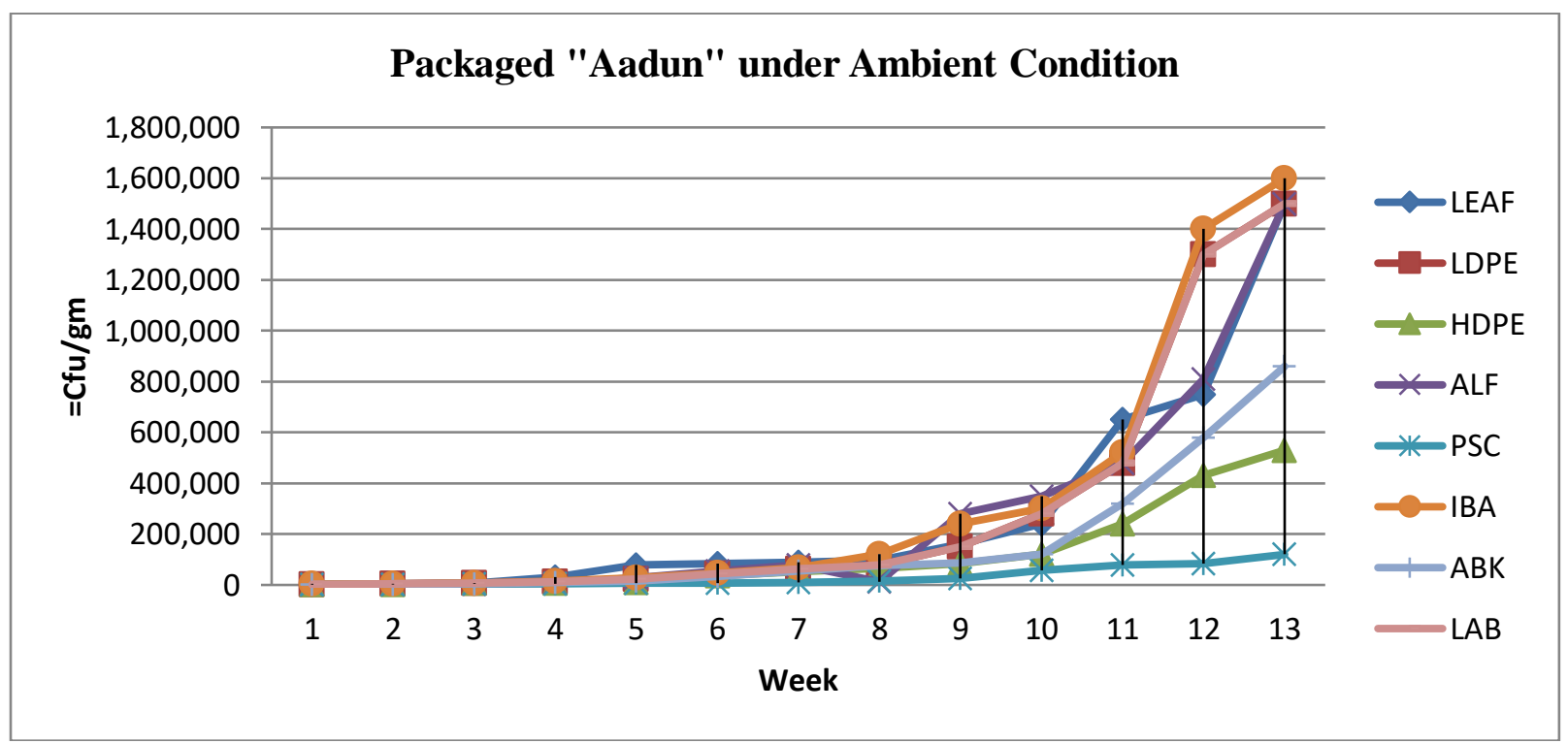

Figure 6: Microbial growth (TPC) under Ambient condition graph.;

Packaged Samples:

1. Laboratory (LEAF, LDPE, HDPE, ALF, PSC); 2.IBA= Ibadan (LDPE)

3. $\mathrm{ABK}=$ Abeokuta (LDPE). 


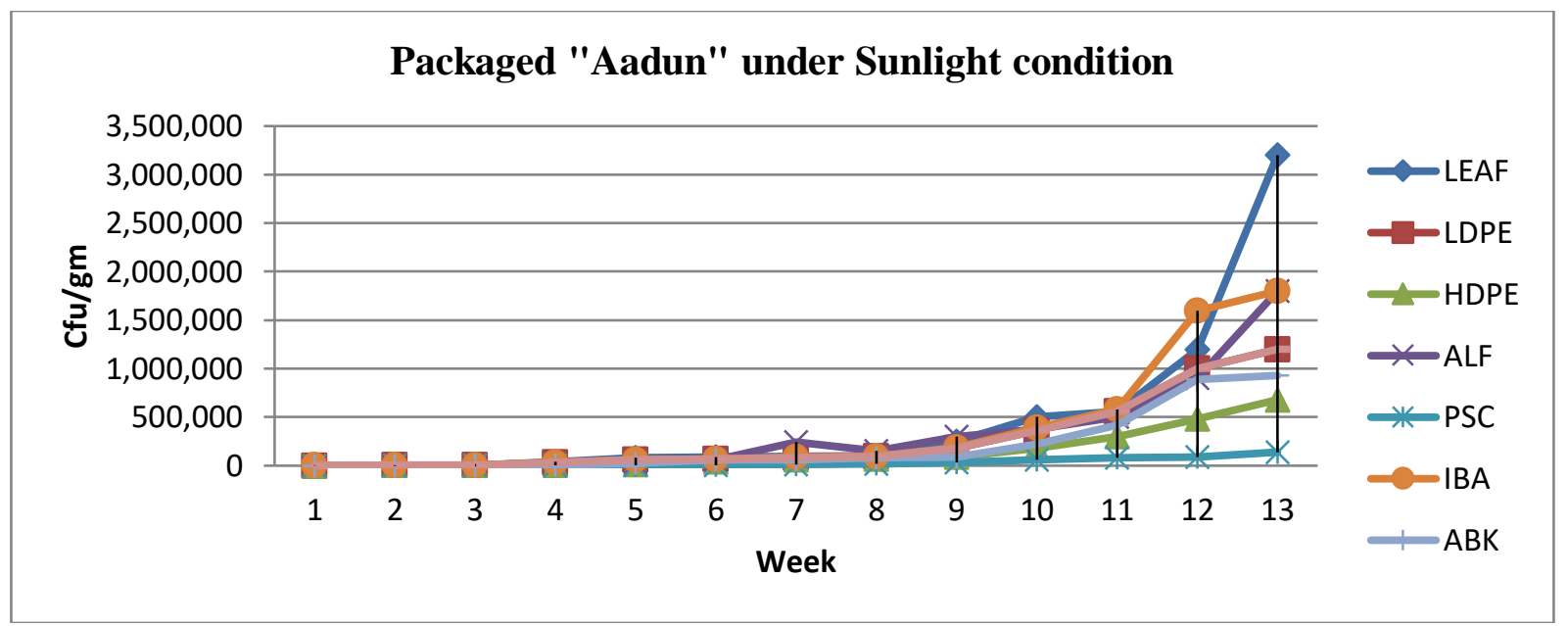

Figure 7: Microbial Growth (TPC) under Sunlight condition graph

Packaged Samples: 1. Laboratory (LEAF, LDPE, HDPE, ALF, PSC); 2.IBA = Ibadan (LDPE) 3. $\mathrm{ABK}=$ Abeokuta (LDPE).

Also, individual packaging materials barrier properties against oxygen and water that can encourage microbial growth was exhibited. PSC plastic materials showed a lowest rate of growth of microorganism under all the conditions of storage which could have been attributed to its higher barrier properties than other plastic materials and leaf [2, 9,22] who had earlier suggested that polymer exercise different barrier properties as a result of varied permeability/ pore sizes of which PSC has lower permeability than LDPE and HDPE. However, leaf and ALF gave the highest rate of growth probably as a result of the high porosity of leaf $[6,15]$ and defects noticed in the molding ALF to cup that leaves gaps for free entry of air to the "aadun". While LDPE packaged Abeokuta had lower rate of microorganism growth even under ambient and sunlight condition which must have been contributed by the heating method which reduced the initial microbial load as suggested that heating process could be used to eliminate some microorganism in foods [3, 16-18].

\subsubsection{Shelf Life Estimation}

The estimated shelf life of "aadun" in different packaging materials and under different conditions is shown in table 5. The estimated result showed that "aadun" could store longer under refrigeration condition which was encouraged by lower temperature that slowed down the process of enzymatic and microbials activities that could have shorten the shelf life of food products [7]. The shorter shelf life noticed under ambient and sunlight conditions respectively was due to favourable temperature that encourages off flavor and microbial growth.

Table 5: Estimated Shelf life of "Aadun" Samples

\begin{tabular}{|l|c|c|c|c|c|c|c|}
\hline CONDITION & LEAF & LDPE & HDPE & ALF & PSC & IBA & ABK \\
\hline REFRIGERATION TPC (week) & 19 & 40.1 & 36.9 & 36.9 & 42.4 & 30.5 & 33.2 \\
\hline AMBIENT TPC (week) & 4.9 & 5.4 & 6.3 & 4.9 & 14.6 & 4.9 & 6.3 \\
\hline SUNLIGHT TPC (week) & 4.7 & 4.9 & 5.9 & 4.7 & 13.6 & 4.7 & 5.3 \\
\hline Average & 9.5 & 16.8 & 16.4 & 15.5 & 23.5 & 13.4 & 14.9 \\
\hline
\end{tabular}

Packaged Samples: 1. Laboratory (LEAF, LDPE, HDPE, ALF, PSC); 2.IBA = Ibadan (LDPE) 3. $\mathrm{ABK}=$ Abeokuta (LDPE). 
Traditional packing of "aadun" and the recent packaging in LDPE has been shown to give "aadun" shorter storage period even under refrigeration condition and even more shorter under ambient and sunlight conditions respectively, their lower barrier properties to oxygen and water might have contributed to this results. However, PSC behavour was different as it exhibited higher potential to store "aadun" for longer period even under ambient and sunlight condition in contrast to LDPE, HDPE and ALF under different conditions. The high barrier properties of PSC must have contributed to shielding "aadun" from internal and external hazards. Meanwhile, the LDPE packaged "aadun" compared showed that Ibadan sample had shorter shelf life followed by Abeokuta and Laboratory sample stored longer in all the conditions of storage which could be attributed to the processing method and level of hygiene to bring this variability.

\section{Conclusion}

It could be concluded from the following that:

1) Consumers will accept "aadun" prepared using modern technology and hygienic condition than the use of traditional technology.

2) Consumer will also prefer the use of PSC plastic packaging materials for "aadun" rather than use of traditional known packaging materials of Leaf and LDPE.

3) Storage of "aadun" under Refrigeration and ambient temperature could allow longer stability for "Aadun" than storage under sunlight before spoilage occur

4) PSC plastic cup rather than the use of Leaf and LDPE increase the shelf life of "aadun".

\section{References}

[1] Akinjogbin. I. A. Some Discarded Food Items of Nigeria Historian perspectives. Paper presented at the $84^{\text {th }}$ annual Conference of the Nigerian Institute of Food Science and Technology, held at the Uni9versity of Ife, Ile- Ife, Osun state, Nigeria, 1984.

[2] Ballantyne, A. Modified Atmosphere Packaging of Fruits and Vegetables. Campden Food prevention research Association, Chipping Campden, England, Publ. 1986, 1-13.

[3] Bibek Ray. Factors affecting micro-organism growth. In Fundamental Microbiology by Bibek Ray, Published by PLB publishers, USA. 2000, 23 -59.

[4] Catherine Bonazz, and Elizabeth,Dumoulin. Quality Changes in Food materials, As influenced by drying Process. Modern Day Technology Vol. 3. Product Quality and Formulation First Ed, Edited by Evangelos Tsotsas and Arun S. Mygun. Wiley-VCH verlog GmBH \&Co. KGaA.2011.

[5] CODEX. Codex Standard for cereals, pulses, legumes and derived products; Codex Alimentarus, Vol. xviii, 1990.

[6] Food and Agriculture Organization (FAO). Appropriate food packaging solutions for developing countries, Rome.2014, 11.

[7] Fu, and Labuza, T.P. Shelf life prediction. Theory and application. Food Control, 4(3),1993, 125133.

[8] Gacula, M.C. The design of experiment for shelf life study. J. Fd. Sci.40, 1975, 400- 403.

[9] Gordon L, Robertson. Food packaging and shelf life: A practical guide. CRS press Taylor \& Francis group, Bola Raton London New York 2010, 5-6.

[10] Harrigan, W.F, McCane, M. Laboratory methods in food and dairy. Microbiology; Academy Press Inc. London Ltd, 1982, 482.

[11] Henshaw, F.O. and Imedioha, C.N. Shelf life studies of Some Nigerian Indigeneous Snack Foods, Die Nahrung, 36, 1992, 403- 407. 
[12] Idowu, M.A and Adedokun, S.O. E valuation of Effect of Formulation, Packaging Materials and Storage Conditions on Chemical properties of "Aadun" (Maize Based Nigerian Snacks). ASSET (University of Agriculture Abeokuta) Publication, 2, 2011,55-58.

[13] Larmond, E. Laboratory Methods for the Sensory Evaluation of Foods. Canada Development of Agriculture, 1837, 1977, 41- 53.

[14] Mathew Whilton. Packaging. Food Cycle Technology Source Books. Intermediate technology Publication in Association with the United Nations Development Fund for women (UNIFEM), 1996, 1-32.

[15] Matz, Samuel, A. Packaging: Bakery Technology Packaging. Elsevier Jan Publishers. Q/A, 1989, 10-36.

[16] Oyewole, O.B, Odunfa, S.A. Microbiology studies of cassava fermentation for Lafun production. Food micro, 5, 1988, 125 -133.

[17] Sanni, Lateef. Specification sheet or Sodium Chloride; Quality Assurance System in Food industry; (Rev.Ed) Jedidiah publishers, 1999, 35.

[18] Sanni, O. Lateef, Bamgbose, A. Christiana and Sanni A. Salifat. Production of Instant Cassava Noodles. J. Fd. Tech, 2 (2). 2004, $83-89$.

[19] Sewald Mark and DeVries Jon. Food Product Shelf Life, How long before Its Gone? In Take You into the Heart of a Great Resource, 12 (2), 2003, Spring www.medlabs.com.

[20] Stone H and Sidel, J.L. Sensory Evaluation Practices; $2^{\text {nd }}$ Edn. Academic Press Inc. 1993.

[21] Uzochuckwu, V.A, Abiodun, M.O, Imman, E.O, 2003. Estimation of shelf life of cooked foo-foo sold in Nigeria; J. Trop. Sci, 43, 2003, pp, 1-6.

[22] Valentina Siracusa. Food Packaging Permeability Behaviour: A Report of International Journal of Polymer Science Volume 2012 ID 302029, 11 pages.

*Corresponding author.

E-mail address: lanesolar@gmail.com 